\title{
Interview with Peter Gallagher of Deloitte Consulting
}

\section{Peter C. Gallagher}

is a seasoned business and information technology professional with 15 years of expertise in the Media \& Entertainment Industry. $\mathrm{He}$ is experienced in working with $\mathrm{C}$-level clients to diagnose their strategic, operational and technological issues and develop innovative solutions to address them. He is also proficient in large-scale program management and strategic planning. Peter focuses on enterprise content management solutions.

Keywords: broadcast DAM, advertising, agency, DRM, rights clearances, licensing

Abstract In our interview with Peter Gallagher, Senior Manager of Deloitte Consulting, we touch on the many developing areas in marketing encompassed by digital content solutions: digital workflows, production and distribution; new developments in magazine publishing; monetizing social media and user-generated content; and key trends in the broadcast arena.

Journal of Digital Asset Management (2008) 4, 291-297. doi:10.1057/dam.2008.36

MM: We're here with Peter Gallagher, Senior Manager of Deloitte Consulting. Peter, would you just give us a little background in terms of yourself and Deloitte?

PG: I have 15 years of experience working in the technology/media and telecommunications industry group. I'm primarily focused on the media and entertainment sector.

I have spent the last ten years focusing on "digital content solutions." Helping companies transition from legacy-type products into more of digital workflows, digital production and digital distribution.

I work for Deloitte Consulting, which is one of the largest consulting firms in the world. Deloitte focuses on business advisory services and consulting, tax audit and financial advisory services.

MM: In what particular area, or is there a particular industry that you're taking the lead in? PG: Media and entertainment. Within that, a focus on publishing, broadcast and sports.

MM: Could you give us a quick reprise of each of those three industries in which you're working?

Peter C. Gallagher Deloitte Consulting LLP, 333 Ludlow Street,

Stamford,

CT 06902, USA

Tel: 9144943038

Fax: 2037055049

E-mail: pcgallagher@ deloitte.com, URL: www. deloitte.com
PG: I've been helping magazine publishers, newspaper publishers and book publishers. Really, everything from content ideation all the way through content distribution. Broadcast has been much more in content production preparing for playout. In sports, content licensing, trademark licensing and branding.
MM: Could you summarize the development or evolution of digital asset management (DAM) in the magazine vertical?

PG: Originally, people had workgroup solutions. Even when organizations tried to work toward enterprise platforms, they implemented DAM as a standalone system. There was a lack of integration with other products. Now that the understanding of DAM has matured and people have become more robust in their understanding, there is certainly a need to have these systems integrated with others.

People have been working to answer complex business questions such as, "What type of products do I have available in certain formats that I can distribute across this geographic channel in this format for this type of demographic?" Answering these questions without integrated systems has been manually intensive and time-consuming. What I am now seeing in the marketplace, is people trying to bring all the different components together: DAM, Rights Management, Production/ Scheduling and Finance, to answer those critical questions.

MM: What have you seen in the publishing area — aside from what you've just referred to in the magazine area?

PG: People who generate their own content are trying to repackage and understand the sub-rights of the things they've done, so that they can create new offerings. Other people 
who have been licensing content are trying to better exploit the licenses they have with authors and photographers. The focus is really on business analytics. Understanding within their inventory and their DAM system, the areas of greatest opportunity.

MM: Something that follows from the traditional focus of DAM is what's commonly referred to as "content optimization." It's about how we classify content that we've published to the web. To light it up for various search optimizations - and therefore monetize it vis-à-vis Google Adwords and/or other ways of monetizing or inducing some sort of transaction?

Could you speak for a moment on some of the technical issues or business issues as they relate to the traditional focus of DAM with its heavy emphasis on clean, well-defined, wellprofiled components with metadata, and content optimization, which is really about tagging things or search engines?

PG: Yes. The balance lies in understanding the constituency of who's going to search, how. Many companies struggle when they try to make that leap. They have a firm understanding internally of how people search through specific fields - or even subjects or concepts that are associated with content elements. But those concepts and the things that are in the internal vocabulary don't always translate well externally.

Companies sometimes struggle with the balance between value-added activities and the cost of tagging. Companies have tried to understand from their partners in the industry how to best address multiple needs. How do their constituents search for content - and leveraging their online partners to understand that. Using tools like thesaurus and other tools to do the tagging upon ingestion - to minimize the amount of effort to tag everything appropriately.

MM: I imagine that also highlights a set of rights management issues. Could you speak a moment about how companies are beginning to think through and deploy technologies to managing various rights such as that? PG: Companies are continually challenged to understand the rights that exist for the content. Once they've gotten over the digitization hurdle and they've catalogued the inventory in DAM, they've now said, "How can I begin to use this content?" The rights management issues are ongoing. People in the business are not in the position or trained to interpret legal obligations and legal restrictions of contracts.

Organizations are trying to move toward solutions that abstract those legal terms and conditions into standard language that can do conflict checking or permissions-and-clearance as a first tollgate. To understand, "Can I use this content or this product in this particular channel, in this language or in this format?" MM: A rights thesaurus would have standardized nomenclature for typical deal points, typical aspects of an IP right. That would then be associated with a bunch of different common uses. Then you could backfill or flag the standardized nomenclature. So you've got standardized nomenclature across a number of contracts. Is that a fair summary?

PG: It's not even for the exploitation of individual pieces of content. It's also to understand gaps in the inventory for exploitation. Being able to take all of those dimensions of rights and say, "Are there elements in my content inventory that I'm not exploiting and that I don't have agreements for in certain geographic territories for certain distribution channels or platforms?"

It's not only in the authorization of permitted use. It's also in the business analytics of understanding what I have in my inventory that I have yet to exploit.

MM: Could you speak a little more in terms of some of the underlying strategies or technical capabilities for managing rights information?

PG: The solutions can vary based on your type of business and the types of content that you produce. Certain broadcast, theatrical and film agreements are very complex. Companies that have this situation probably have the biggest pain in implementing those types of solutions. Their strategy has been to focus more on core or key requirements to support business development and legal operations upfront, to minimize the amount of time it takes to research and get the appropriate answers to key business questions. In other organizations where rights are simpler, their strategy has been to simplify the thesaurus, as you call it. Simplify the rights definition so that I can push the decision-making further out to the edge, and allow people on the line business to make 
decisions, rather than have to go through a central clearinghouse.

MM: So that begins to automate the whole clearance process. Perhaps just in baby steps, but meaningful steps, nonetheless - allowing people out, as you say, to the edge.

PG: The maturation process for business rights solutions compares nicely to DAM solutions. In the beginning of enterprise DAM, people were hesitant to share content for fear of how it was going to be used. After people began to see the benefits of having content available and standardized, new offerings came to market. We're starting to see that same evolution in the rights management space.

It used to be that only certain elements of the business were allowed to make rights clearances decisions. But as the landscape has changed, legal departments are starting to at least put the information out in the hands of the end-user. We will see fluctuations in where decision making really lies, but there begins to be a shift in thinking.

MM: Regarding how rights information management has matured along the lines with DAM. Overall, it's made it much more transparent and clear about how people are using digital assets, and under what business conditions. Therefore, many companies are feeling much more secure, and therefore much more open in terms of how to share these with partners or advertisers. Is that a fair characterization?

PG: Yes.

MM: With respect to the emergence of digital supply chains for content and specifically for publishing, could you share with us some of the insights that you had working with clients and perhaps focusing on key trends, developments of what we're now referring to as digital supply chains?

PG: Sure.

What's really becoming a market trend is content producers and their digital value chain, wanting to go direct to the consumer. This lends a lot of different challenges for them. They're generally in the content business or the content production business, and do not always have relationships with customers.

Just because you can go direct-to-consumer doesn't mean that you should. The cost of infrastructure and technology could be excessive or cause other implications to your business.

We've been working with customers focusing on the core capabilities of the business, what the things are that you need to innovate on with content production tools, support distribution, and then really deciding what partners or third parties you should partner with to bring your content to the consumer, rather than try to make all those investments yourself.

MM: Focusing on the magazine publishing — as a place to start - it seems to me that the digital supply chain for a magazine publisher falls into five basic categories. Let me outline those quickly, and then you can speak to them.

Working backwards from the experience of consumers as they live, work and play - the first area that I'd characterize is brand space. Brand space is the socialized dimension of the web. It really reflects fundamental demographic and psychographic changes in media consumption.

Then as we move back into publishing organizations, the next part that we encounter and start to look at in terms of a digital supply chain is what I'm calling the "engagement theater."

The engagement theater is a metaphor that I use to describe the user experience, information architecture and the brand voice of a publication. In this case, a magazine. The engagement theater is where a consumer begins to engage and interact with content, with an idea of really facilitating the engagement into deeper and deeper consumption patterns of the content.

You'd have perhaps what I'll call "content optimization groups." The content optimization group is really about text mining and tagging and cross-tagging. Converting content into cash. Specifically being able to take years of editorial content that might have been published, and creating logical collections from it through text mining and other sorts of automation techniques.

One of the things that falls out of that is what some people refer to as an ontology and a taxonomy for how these various bits of content all come as a meaningful collection for a particular consumption profile. Then, moving upstream from that, we have what I'll call the "content refinery." 
The content refinery is where the basic editorial content from a magazine gets broken down into its smallest reusable chunks. What I might call "intelligent sub-assemblies." Those intelligent sub-assemblies may include formatting text, metadata, metatagging and that sort of stuff. But it all exists in a tagged XML data repository.

Then furthest up, you basically have editorial operations. Editorial operations are really what I'd call multichannel and multimedia editorial operations. That's where we get the photo desk and the layout tools.

But it also includes the picture or photo desk and - increasingly — user-generated video and other sorts of things. Does that fairly represent a broad brush basic structure of a digital value chain for publishers? Specifically, magazines?

PG: Sure.

MM: Using that, what are some of the key developments that you've seen in terms of this multimedia and multichannel editorial operations in terms of automation and the use of DAM, there?

PG: There are variations in the editorial operations area. People are deploying tools to improve the methods for feeding content into their refinery. Rather than create content in distribution-specific platforms, organizations are creating content or deploying tools to transform content so it can go into the refinery in a more optimized way. This helps reduce conversion costs downstream.

From refinery to optimization, it really has a distribution channel in mind. I think that this ties to your branding engagement layers. In certain instances, branding engagement will be an important element. If you have a strong brand that drives people to value and trust your content, then consumers will seek out your brands. That is one element of the packaging that needs to happen in the optimization layer.

But I think that there's another dimension. There are instances where people are looking for content based on certain subjects or other key elements instead of brand. They don't want to have to hunt and peck across multiple sources. The main driver is speed and relevance. Content could come from multiple sources.

The optimization layer and packaging needs to not only support the distribution toward your brand-centric platforms, but packaging content to support third-party relationships for syndication.

MM: Absolutely. That's a great summary.

In any one of those, would you like to take it to the next level in terms of the content refinery? What are some of the organizational challenges, both facilitating and hindering factors for really taking the content refinery or content optimization to the next level?

PG: Understanding the core elements of your content, and its lowest levels of decomposition. With this in mind, just because you can decompose something to its lowest level or normalize it doesn't make sense? The cost to convert, tag and ingest may not be justified.

One reason people struggle is a lack of understanding of their content distribution. If they understand their distribution channels, they will understand what the core elements of their content are. Again, understanding those distribution channels will also help them understand what metadata standards they need to implement.

Right now, many organizations are focused on anything and everything around subjects and tagging. That really may not be necessary.

One approach to keeping costs down and have the optimization layer truly optimized is to have a strong sense of where your content's going and how it's being consumed. So at least people have focus and direction.

MM: That would make the case, Peter, that content strategists and planners and/or digital strategists or publishing operations really have a pretty explicit, well-defined set of channels. We're defining "channels," as a content endpoint to which you need to optimize content for comprehension, consumption, retrievability, search and so on.

The idea would be that you start at a content endpoint, like a mobile phone. Or a Wii - a video game. Or an iPhone or a mobile laptop running a browser. Then, working backward from that content endpoint, back into the content factory - which would be the engagement theater - the content optimization, the refinery and so on. Is that a way of summarizing what you're saying?

PG: In one aspect, it is.

I'm trying to say that starting with those distribution points, you need to look at the 
capabilities that are needed within the different layers of your business, and what the implications are, based on how people consume content.

If we take mobile phones as an end platform, it may not make sense for a content-certain organization to own every element or every layer in that distribution value chain. But understanding how people consume the content and the brand at the end will help you define the business capabilities. Then, understanding long term what you need to support, those will help drive your technology decisions.

For example, if I understand that I need multiple conversions to help on my content as I push it out to different handsets, I may decide that I need a sales force for business operations to support that function. But from a technical standpoint, I'm going to outsource that capability to a conversion house. I don't want to invest in those platforms in my optimization layer in the near term, because it's not going to be a core capability for me, moving forward.

There tends to be a proliferation or a manifold of new playout devices that require constant engineering.

And is that really the type of capability that a content creator should be focused on? No. They should be focused on creating high-value quality content that's platform-agnostic. Then, to rely upon those third-party distributors to do the conversions.

MM: Who are some of the third-party playout or conversion centers that probably fit in the digital ecosystem for publishing?

PG: Well, they're still emerging. There are players that are emerging in the short term, but long term I think you'll see a different set of players. In the short term in publishing, you're seeing digital warehouses - LibreDigital and some other partners - that publishers are using to support that conversion and distribution process.

If you look long term, as content begins to collapse and converge - whether it's video publishing, etc. I think you're going to have to see larger-scale players making investments be it the Telco's, the cable companies who are going to own the infrastructure, and the delivery mechanisms.

MM: Well, that goes to the rationale why Comcast bought "The Platform." The platform being a multimedia playout center with a heavy emphasis on video.

PG: Exactly.

MM: Speaking in terms of the publishing world, how do distributors like an Amazon or an Ingram Books play in terms of that digital supply chain, specifically at that content endpoint?

PG: Certain organizations will be the primary customer-facing platform. The Amazons and the Googles will become the virtual retailer of the content - the place where people go for a portal-to-brand-centric content. Or it could be going to that as a source for subject-based content.

Then, the other players, wholesalers and distributors, may be a supporting party in value chain for certain types of content or products.

A wholesaler may choose to focus more on being that party that supports publishers to do the conversions, and then feeds it to the actual infrastructure player who's going to deliver the content. I think you'll start to see people into more specific roles rather than trying to own the whole value chain from creation through customer relationships.

MM: What would you like to address next in terms of key developments and trends? In the engagement theater, information architecture and brand voice? Any key organizational challenges or upcoming disruptions you see in that particular area?

PG: One emerging trend is the high degree of understanding that interactive elements provide competitive advantage. If you are a traditional publisher of text or other print products, that and that alone will not support those engagement platforms. You need to build other interactive tools that will keep people engaged with your content.

For example, if I have an article about a recipe, content providers need to wrap tools around it to drive interest. The content standalone does not provide competitive advantage. Those interactive elements are really things that are important to help supplement the content in the engagement layer.

MM: I had an interesting conversation with someone who was part of a strategy team for a large magazine publishing operation. They specifically had a lot of hobby and vocational fan magazine properties. 
One of the things they shared with me was that — first of all — the magazine business is really different in the US than it is in Europe or Asia. Here in the US, the post office subsidizes the delivery of magazines. In Europe, you've got to pay the full freight. So oftentimes you're paying the equivalent of $\$ 3.00$ or so to deliver a magazine subscription copy in Europe.

So the net result is that business models tend to be really different. In Europe, the primary means of distributing magazines is the kiosk. Because of the mass transit systems, kiosks play a really large role in terms of showcasing and launching a new magazine.

So, a magazine publisher in Europe - upon launching a new magazine property - knows within two to three issues whether they're going to have a profitable magazine. In the US, it takes ten times longer. It takes often several years of heavy promotion and significant upfront investment with the idea of really driving subscriptions before you really understand whether you've got a magazine or not. That means it's a high-risk proposition to launch a magazine in the US.

One of the things that we're now tracking is that magazines - specifically the ones that really have tightly focused "tribes," or fan clubs - these magazines are now creating social media portals. Blogs, forums, uploads of photos from your mobile phone or camera, as well as videos.

The idea of what they're doing is to identify a potential new audience. They build an audience online. In the course of building that audience online, part of that is getting regular newsletter subscriptions, as well as fan participation and social media.

As soon as it gets up to a certain threshold, they know they can then successfully launch a print magazine to monetize the community. This basically says, "As a magazine publisher, you need to have to have a whole social media strategy with an infrastructure that really highlights user-generated content. You need a semi-loose governance in terms of editorial control, and you need to handle and process user-generated photos and videos that may well show up in quantities of 5,000 or even 10,000 submissions a month."

Could you speak to some of the challenges that magazine publishers now have as they transition into a multimedia workflow or a multimedia process?

PG: Yes. If we look back at your five-tiered model with brand and engagement, one of the key elements here is having the balance between user-generated content and also your high brand-value content.

So if you rely heavily on user-generated content, how does that align to your brand? Are you going to be true, and build your brand appropriately?

The first thing is, you need the right balance between internally produced content and usergenerated content. This has a great impact on the refinery and optimization layers.

As your brand becomes more visible and more people want to participate in submitting content, there's obviously greater impacts to your operation from being able to filter that content, review it and find out if it meets your brand standards.

One thing that people are trying to do is to have very focused areas of submissions. From a tools standpoint, to control and tag content as it comes in - so that the focus can be on reviewing the subject matter, rather than having to manipulate and play with the data and the content, itself.

MM: Doesn't that speak, then, to the need to have a lot more automation on the front? Otherwise, you're just going to have to hire armies of people to approve each of the submissions.

PG: Absolutely. You need a separate type of person. Not only an editor to do review, but you need someone who can do manipulation and conversion. So I agree - you want people to be able to focus on the high-value activities and automate those activities that really aren't value-add.

MM: One of the other things that becomes an interesting development with respect to usergenerated video is methods of monetizing it. I haven't seen this too much at YouTube, but I've seen it at another video portal called Veoh.com. We're seeing that as they upload videos, they now sell sponsorship — pre-roll or post-roll.

What sort of things have you seen in terms of how to create incremental revenue around user-generated video?

PG: Deal with the challenges of managing the sponsors, in trying to keep the user-generated 
content aligned to the brand sensitivities of the sponsor. Again, those brands that you mentioned are also careful about their image and how certain user-generated content elements could impact their brand if there's a negative connotation to them.

There's certainly a balance between which sponsors are willing to get involved in usergenerated content, and which properties are still leaning toward that brand-created centric content of the property, rather than user-generated.

MM: Peter, as we start to move toward the conclusion of our interview here, are there any other thoughts in terms of breakthrough business strategies or transformational applications as they specifically relate to the publishing supply chain?

PG: I think people need to re-evaluate their platforms investments. What are the key capabilities that they have or need to innovate? It could be core production capabilities such as rights management, DAM, content production.

Content producers should also think about the new platforms for transport and distribution that will be necessary to support third parties that we perform distribution. These are the business capabilities that may be outsourced.

How do you innovate your existing capabilities and build on to your new capability? MM: Are there any particular distribution endpoints or revenue channels that media and entertainment firms have particularly made important, to make operational in the next year or 18 months?

PG: I think certainly supporting online or interactive advertising models continues to be an area of interest to people. "How can I produce content and support the different advertising model for that platform?"

The price points and consumer demand still have a level of uncertainty across different distribution channels. But advertising is certainly an area that's a bit consistent. Interactive advertising and online advertising is an area where companies are continuing to expand and explore. It seems as though people are trying to look at how to best exploit those dollars, and that's helping them feed their decision process.

MM: Beyond the traditional banner ads or interactive versions of banner ads, and/or ad keywords, what are some of the other strategic options that have now emerged in online or interactive advertising opportunities?

PG: One is embedded advertising within gaming. "What content do I have that I can either license to support interactive gaming?" Or, "How can I use my content to create games, themselves, and have embedded advertising in that platform?"

MM: Again, Peter - thank you very much for the time today.

PG: Thank you, Michael. 